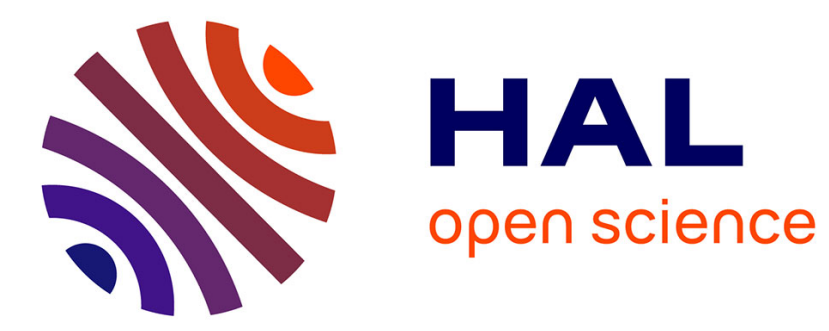

\title{
Pedagogical Interaction Management Using Wireless Technology
}

\author{
Rémi Legrand, Michèle Joab
}

\section{To cite this version:}

Rémi Legrand, Michèle Joab. Pedagogical Interaction Management Using Wireless Technology. ICTTA'04: 1st International Conference on Information and Communication Technologies: From Theory to Applications, Apr 2004, Damas, Syria. pp.127-128. lirmm-00108817

\section{HAL Id: lirmm-00108817 https://hal-lirmm.ccsd.cnrs.fr/lirmm-00108817}

Submitted on 23 Oct 2006

HAL is a multi-disciplinary open access archive for the deposit and dissemination of scientific research documents, whether they are published or not. The documents may come from teaching and research institutions in France or abroad, or from public or private research centers.
L'archive ouverte pluridisciplinaire HAL, est destinée au dépôt et à la diffusion de documents scientifiques de niveau recherche, publiés ou non, émanant des établissements d'enseignement et de recherche français ou étrangers, des laboratoires publics ou privés. 


\section{Pedagogical interaction management using wireless technology}

\author{
Rémi Legrand \\ Université Pierre-et-Marie Curie (Paris \\ VI) \\ Bur. C266 - 8 rue du Capitaine Scott \\ 75015 Paris - France \\ legrandr@ccr.jussieu.fr
}

\author{
Michelle Joab \\ LIRMM, Université Montpellier II \\ 161 rue Ada \\ 34392 Montpellier cedex 5 - France \\ Michelle.Joab@lirmm.fr
}

\begin{abstract}
The interactions between the teacher and the students are central within face-to-face learning. However little of this interaction is written down and kept for further use. In this paper we propose to computerize some pedagogical interactions occurring in class, so that the learner could store all the results of the pedagogical activity. Furthermore, the teacher is able to complement and go through the pedagogical resources for future uses. Our paper studies the contribution of a wireless classroom, and presents the hardware and software required to implement them. An experiment schedule and the first results are presented in order to study the feasibility and interest of our approach.
\end{abstract}

\section{Introduction}

Today, new information and communication technologies for education (ICTE) contribute to improving the pedagogical activities during a lecture/recitation class. The progressive integration of these technologies into face-to-face learning addresses the issue of their sensible use in order to adapt investments and to build innovative pedagogical processes. In this paper we propose to computerize some pedagogical interactions occurring in class, so that the learner could store all the results of the pedagogical activity. Furthermore, the teacher is able to complement and go through the pedagogical resources for future uses. Our paper studies the contribution of computerized interactions during a class, and presents the hardware and software required to implement them.

Local networks in a pedagogical context have been widely developed, but are mainly dedicated to lab class. New technologies extend the use of ICTE to any kind of classroom. Among the reasons why they have been spreading, we can quote wireless networks, the fall of the cost of hardware and the use of new software which are easy to customize. The remaining issues of security and capacity are to be dealt with and are less critical in our context. The devices considered here are a videoprojector, laptops and interactive whiteboard or tablet PC which enables handwriting. All these devices may be connected through a wireless network.

Very early research has been done exploring the pedagogical uses of the wireless classroom [1, 2]. In the Wireless Classroom, the students used laptops equipped with a wireless card, speakers and microphone; the teacher had a video camera, a microphone, a projector connected to his laptop. In addition, he may use a writing device (an artpad). The classroom has several wireless access points. They encountered many technical locks which slowed down its development. For example, the performance of the wireless networks was unacceptable to deal with transfer of multimedia interactive documents mixing images, video, audio (from 2Mbps in 1998 to 10 Mbps today)... The technology was not mature enough. We can quote for example, the weak reliability of batteries and the weak quality of the drawing devices.

Today, mobile and wireless devices are extensively included in new pedagogical organizations [3, 4]. The frontiers of the classroom are not clearly defined. In the Ubi-Learn Project [5], the students may be inside or outside of the virtual class. They are equipped with a computer or any mobile device. They can interact with other students and any professor.

In section 2, we describe the contributions of these technologies to the pedagogical activities in a class. Section 3 presents equipment and human costs involved. Section 4 presents an experiment schedule and the results of our first experiments in order to study the feasibility and interest of our approach.

\section{Contributions of new technologies to pedagogical activities in a class}

The interactions between the teacher and the students are central within face-to-face learning. However little of this interaction is written down and kept for further use. Within a fully equipped classroom, the teacher projects slides and comments on them with annotations arising from the interaction with the students. A videoprojector is connected (with a wireless connection) to the teacher's tablet PC, so he can move through the classroom with the latter. To handwrite annotations, he uses his tablet PC or an interactive whiteboard. He can also associate oral annotations to a 
slide, following an interaction. The teacher assigns a status to an annotation according to its final use: forwarded to the students without modifications, corrected then forwarded, considered anecdotal and not forwarded.

In an equipped classroom, students use their laptops to visualize and annotate the current slide displayed by the videoprojector. They can also go back to the previous slides. They manage three layers of documents: the initial slides displayed by the teacher, the annotations given by the teacher and immediately forwarded, and their own annotations. A few other tools are needed to manage annotations and layers when they overlap, or to allow a student to send an annotation to others. The oral and handwritten annotations are stored either as images and sounds, or after being recognized by a dedicated program. Students can ask questions from their laptop. The teacher sees them on a control panel with the name of the student.

He decides whether he displays them on the interactive whiteboard. Then, the teacher selects the questions he wants to answer and/or store. It is possible for the students to join in to a question displayed on the interactive whiteboard, to support it. Some questions are differently managed such as the lack of understanding which are anonymous questions and are indicated to the teacher through a threshold mechanism. Sometimes, a student can directly ask a question to peers through the network, because their answers are often more simple to understand. The control panel is to be experimented to assess the additional cognitive workload required from the teacher and the students. We also have to evaluate how much these functionalities help the course of the class.

At the Kentucky University, the Wireless Project [1, 2] experiments very near functionalities for sharing annotations, questions, answers on a whiteboard. Unfortunately, the project faced many technical difficulties which slowed down any spreading of wireless classrooms.

Our study is concerned with collaborative work in pedagogical situations. For instance, during recitation class, several correct solutions could rise from proposals made by students. This collaborative work and its associated discussions must be preserved. Indeed, the arguments exchanged and the choices carried out are as important as the solution. After the discussion, it is essential to synthesize the different solutions studied to guarantee their global coherence and consistency.

The use of collaborative work software in a network based classroom enables to reach the following goals: the working out of solutions for each group of students, communication from one group to other groups, global discussion with the videoprojector, shared annotations to exchange arguments and proposals in order to improve the solution. Following this first step, each group has to take into account the global discussion and adapt each solution in order to make it coherent with it.

\section{Equipment and human costs}

Equipment and human costs are successively presented below.

\subsection{Equipment costs}

We assess the cost to fully equip a wireless classroom from the costs of atomic components detailed in the table below. They give a rough estimate of today, as computer hardware is improving very fast. From the following figures, we estimate the cost of a classroom designed for 30 students. Each student uses a laptop or a Tablet PC. The teacher uses a Tablet PC, an interactive whiteboard and a projector. In addition, we need a few access points connected to Internet. According to that, the total cost amounts to $67500 €$ $(1 €=1,2 \$)$.

\begin{tabular}{|l|l|}
\hline \multicolumn{1}{|c|}{ Device } & \multicolumn{1}{c|}{ Cost } \\
\hline Laptop with a WIFI card & from 1000 to $2000 €$ \\
\hline Tablet PC with a WIFI card & from 2000 to $3000 €$ \\
\hline WIFI card & About $80 €$ \\
\hline $\begin{array}{l}\text { Interactive whiteboard } \\
\text { (for a recitation classroom) }\end{array}$ & from 1000 to $2000 €$ \\
\hline WIFI access point & from 100 to $300 €$ \\
\hline WEB Camera & 100 \\
\hline $\begin{array}{l}\text { Headphones and } \\
\text { microphone }\end{array}$ & $30 €$ \\
\hline Videoprojecteur & from 1500 to $3000 €$ \\
\hline
\end{tabular}

\section{Figure 1. Device Costs}

Actually, this cost estimate does not correspond to equip a classroom in the future. Indeed, we consider that, in the next years, every student will have its own laptop, the same way he/she has a mobile phone today. The personal equipment of students is taken into account in the French program entitled «Universités numériques en region» (wired campus in regions) launched in 2003. Its aims is to develop a comprehensive set of wired services devoted to all the university users in each region. An important chapter of this program concerns the equipment of the students. For instance, in the region "Rhône-Alpes» a plan (http://www.pampampam.net) initiated by the Greco ${ }^{1}$ aims to offer special rates to the students and teachers. The prices proposed are within the margin given above: $1000 €$ (VAT included) for a laptop with office tools, $1500 €$ for a laptop with scientific or multimedia tools, and $1900 €$ for a laptop with mobile tools. Moreover, specific consumer credits are proposed to the students.

Insofar as the students have their own laptop, the overcost following from the wireless class will be

\footnotetext{
${ }^{1}$ Greco (Grenoble Universités Campus Ouvert) http://greco.grenet.fr/
} 
reduced to the setup of a wireless network throughout the university, with interactive whiteboards and projectors. All these devices cost less than $10000 €$ per classroom.

Above all, the wireless technology permits to wire old buildings and are very well suited to the mobility of students and teachers activities.

\subsection{Human costs}

Once a classroom installation is realized, extra uses are possible. As some interactions are automatized and required less interventions from the teacher. So more students can be added in the class. Even students at distant locations can be synchronously connected to class through Internet network. For these distant students, this framework is a synchronous virtual class, close to a Learning Management System such as LearningSpace 5. That would be adapted to lecture class where the teachers do not interact much with the students. The extension of wireless class which incorporates distant students could be seen as a way to reduce the cost of teaching.

Our approach is the opposite view since we consider that wired classes must be developed in order to improve the interactions. In fact, students generally prefer to attend classes rather than to study from a CDROM. They save time, except in particular cases such as those who are living far from the university, and those who are repeating their year. So, the number of students attending a class does not change whether the lecture slides are available. Contrary to distant learning which enables economies of scale, the wireless class does not reduce costs except for instance when two universities organize a common course so they avoid moving expenses.

To train the teachers is the main difficulty encountered. They must be convinced by the contribution coming from wired campus. They must be motivated to accept to devote their time to that training. The awareness of the importance of a good training will contribute to a better implementation of pedagogical innovations. The cost of this training must be integrated in the global evaluation.

The pedagogical activities described in section 2 produce new annotations coming from the interactions which occurred during the class. Theses annotations must be treated in anticipation of the future uses of the course. To edit and incorporate these annotations is easier because the teacher has stored them. So, the teacher saves time. However, editing an annotation could be tedious and inappropriate to the future courses. The overall waste or gain of time is questionable.

\section{Experiment schedule and first results}

The pedagogical situations presented in Section 2 do not require heavy installation in terms of equipment or wiring.

They rely on existing software (shared editors, handwriting and oral recognition) or small software easy to develop (control panel). We have worked out an experiment schedule to validate the situations encountered by the students and teachers. Each experimental variable is tested in order to validate separately each pedagogical hypothesis. The validation process focuses on the technical feasibility, the usability of devices, the quality and number of pedagogical interactions.

\subsection{Experiment schedule}

During the first half of the year 2004, at the university of Montpellier 2 (France), we are carrying out the following experiments: use of a tablet PC by the teacher to communicate with students in a class situation, use of synchronous collaborative work software in a class situation.

A wireless network will be installed in some buildings by summer time. From September, we hope that we will be able to test the whole wireless classroom.

We will also develop and test the applications in charge of the control panel and in charge of sharing of annotations. After these experiments, we will be able to suggest a software requirements specification to generalize such devices.

\subsection{First results}

Teachers are using a Tablet PC connected to a videoprojector to communicate with students in a class situation. The Tablet PC is used according to their previous ways of teaching.

Some teachers are using it to replace the blackboard and the chalk. They handwrite either during the class or in advance, as they are afraid to use it in real time. There are probably several reasons. They fear that their handwriting could be unreadable or that it will take more time than writing on the blackboard. Probably they don't feel comfortable with the device. Mainly, they teach mathematics or physics and make an intensive use of formula. Once written the course materials, the teachers upload the file on an open source course management system, Claroline (http://www.claroline.net/), in order to make them available to the students.

For computer science courses, teachers often use software as MS PowerPoint to prepare slides before the class. With a Tablet PC, They project slides and comment on them with handwritten annotations arising from the interaction with the students. We observe that teachers use written marks as arrows, circles or 
highlighting items combined with oral intonations during the class in order to catch the student's attention. These marks stress the important items during the class and are not stored. We notice the student are also interested in Tablet PC facilities. It is a promising sign for the next step of our experiments.

We tested another class situation. Teachers use a Tablet PC to gather and synthesize the student responses. The experiment took place during a recitation class devoted to e-learning which focuses on different analysis of the forum. Figures 2 and 3 highlight a linguistic analysis based on Speech Acts [6, 7].

\begin{tabular}{|l|l|l|l|l|l|}
\hline $\mathrm{N}^{\circ}$ & $\mathrm{H}$ & Int. & TEXTE & Th. & An. \\
\hline I12 & $15: 24$ & A1 & $\begin{array}{l}\text { En fait, je pense à un } \\
\text { mode d'évaluation } \\
\text { ressemblant à } \\
\text { l'évaluation du code de la } \\
\text { route à l'examen du } \\
\text { permis de conduire. }\end{array}$ & & \\
\hline I18 & $15: 27$ & A13 & $\begin{array}{l}\text { Faire un examen } \\
\text { ressemblant au permis de } \\
\text { conduire paraît être en } \\
\text { effet une bonne idée. }\end{array}$ & & \\
\hline
\end{tabular}

\section{Figure 2. Slides prepared before the class.}

Figure 2 shows a table extracted from data gathered in a forum. Each utterance is described by its number (first column), its date (second column), its speaker (third column), its content (fourth column), its focus (fifth column) and Analysis (sixth column). During the class, the students have to discuss and to identify the focus and the speech acts involved in each utterance.

We highlight the focus in the content column, handwrite the focus identified in the fifth column, draw an arrow from the content to the focus and finally handwrite the speech act in the sixth column. The results of the work are shown in Figure 3.

\begin{tabular}{|c|c|c|c|c|c|}
\hline $\mathrm{N}^{\circ}$ & $\mathrm{H}$ & Int. & TEXTE & Th. & An. \\
\hline I12 & $15: 24$ & A1 & $\begin{array}{l}\text { En fait, je pense à un } \\
\text { mode d'évaluation } \\
\text { ressemblant à } \\
\text { l'évaluation du code de la } \\
\text { route à l'examen du } \\
\text { permis de conduire. }\end{array}$ & th & $\begin{array}{l}s_{y} \\
y \\
n \\
n\end{array}$ \\
\hline I18 & $15: 27$ & A13 & $\begin{array}{l}\text { Faire un examen } \\
\text { ressemblant au permis de } \\
\text { conduire paraît être en } \\
\text { effet une bonne idée. } \\
\text {. }\end{array}$ & $\begin{array}{l}+41 \\
31.2\end{array}$ & $\begin{array}{l}n \\
p \\
p \\
\eta \\
0 \\
b \\
a \\
t \\
1 \\
0 \\
n\end{array}$ \\
\hline
\end{tabular}

Figure 3. The results of the discussion.

After the class, the completed slides are uploaded on the Course Management System Claroline. The results of the interaction during the class are stored at the end of the class. The trace of the interaction between the teacher and the students is stored on the fly with significant drawings.

The third experiment is focussed on synchronous collaborative work. We try the Virtual Classroom tool in the Learning Management System LearningSpace 5. It takes place in a Laboratory Classroom. Each student is connected through the wired network (we don't yet have at our disposal the wireless network). He/she has a microphone, a webcam and headphones connected to his/her computer. Students try the Virtual Classroom while working on a collaborative task: building a working plan for a software engineering process. The experiment aims at assessing the usability of the Virtual Classroom software in the wireless classroom. We have mixed feelings about this experiment. First, the audio devices are essential for the collaborative tasks involved but they are not convenient in a classroom. When the teacher customizes the Virtual Classroom of LearningSpace 5 in order to allow every student to speak in turn, the control is given to the first speaker. As the microphones catch background noises, the speaker is not clearly identified. The Chat tool may be good enough to communicate. The Virtual Class enables sharing applications. The user control provided is not smooth enough for collaborative work. We have to try other collaborative tools which will be performed through the wireless network.

\section{Conclusion}

We are aware of the issues raised by our proposals. Technically, wireless technology is important because it allows progressive investment. The motivation of the teachers is essential. New aspects of their activities must be well considered: the workload involved, the copyright and broadcasting rules attached to the documents, the evaluation of teacher's work. The use of new technologies must not reduce teaching in a classroom to distance learning. Its features of interactivity and user-friendliness must be preserved while developing the use of the computer tools.

\section{References}

[1] J. Griffioen, W. B. Seales, and J. E. Lumpp, Jr, "Teaching in realtime wireless classrooms," FIE-'98. 28th-Annual-Frontiers-inEducation-Conference. Moving from 'Teacher Centered' to 'Learner Centered' Education, Tempe, AZ, USA, 1998.

[2] J. Griffioen, W. B. Seales, J. E. Lumpp, Jr, and K. T., "Experience Developing Wireless Networks for Interactive Multimedia Instruction," FIE-'98. 28th-Annual-Frontiers-in- 
Education-Conference. Moving from 'Teacher Centered' to 'Learner Centered' Education, Tempe, AZ, USA, 1998.

[3] C. DiGiano, L. Yarnall, C. Patton, J. Roschelle, D. Tatar, and M. Manley, "Collaboration design patterns: conceptual tools for planning for the wireless classroom," IEEE International Workshop on Wireless and Mobile Technologies in Education, Vaxjo, Sweden, 2002.

[4] C. DiGiano, L. Yarnall, C. Patton, J. Roschelle, D. Tatar, and M. Manley, "Conceptual tools for planning for the wireless classroom," Journal of Computer Assisted Learning, vol. 19, pp. 284-297, 2003.
[5] M. Laroussi, "New e-learning services based on mobile and ubiquitous computing: Ubi-Learn project," CALIE 04 Computer Aided Learning in Engineering Education, Grenoble, France, 2004.

[6]J. L. Austin, How to do things with words. Cambridge: Mass. Harvard University Press, 1962.

[7] J. R. Searle, Speech Acts. Cambridge: Cambridge University Press, 1969. 